\title{
Predictors of COVID-19 outcomes in adult congenital heart disease patients: Anatomy versus function
}

\author{
Magdalena Lipczyńska*, Ewa Kowalik*, Magdalena Kumor, Beata Kuśmierczyk-Droszcz, Anna W Wójcik, \\ Elżbieta K Biernacka, Piotr Hoffman
}

Department of Congenital Heart Disease, National Institute of Cardiology, Warszawa, Poland

*Both authors equally contributed to the study

\section{Editorial}

by Schwerzmann et al.

\section{Correspondence to:}

Magdalena Lipczyńska, MD, PhD,

Department of Congenital Heart

Disease,

National Institute of Cardiology,

Alpejska 42, 04-628 Warszawa,

Poland,

phone: +48223434400,

e-mail: mlipczynska@ikard.pl

Copyright by the Author(s), 2022

DOI: 10.33963/KP.a2021.0176

Received:

October 8, 2021

Accepted:

December 9, 2021

Early publication date: December 9, 2021

\section{A B S TR A C T}

Background: It is unclear whether patients with adult congenital heart disease (ACHD) should be considered as an increased risk population with poor outcomes when suffering from COVID-19.

Aims: This study aimed to collect clinical outcome data and to identify risk factors of a complicated course of COVID-19 among ACHD patients.

Methods: Among all outpatients who came to medical attention via telemedicine or direct physician contact at our institution between September 1, 2020 and March 31, 2021, we included all with a COVID-19 diagnosis. The incidence of COVID-19, a clinical course of the disease, and outcome were determined.

Results: One hundred and four (8.7\%) out of 1197 patients who were seen at our outpatient clinic for ACHD patients met the definition of COVID-19. Most of them reported a mild course of COVID-19 (99 [95.5\%]). Five patients (4.5\%) experienced severe symptoms and needed hospitalization. Two patients (1.9\% of all with a confirmed diagnosis, $40 \%$ with severe infection) died. In the multivariable analysis, decreased systemic ventricular systolic function and any significant valve stenosis were predictors of a complicated disease course.

Conclusions: Our study confirmed previous results showing that a physiology-based model, rather than an anatomy-based model, better predicted COVID-19 outcomes among ACHD patients, which is of importance for patients and healthcare providers during the COVID-19 pandemic.

Key words: COVID-19, adult congenital heart disease, outcome

\section{INTRODUCTION}

The novel SARS-CoV-2 responsible for COVID-19 is known to damage the cardiovascular system, leading to increased morbidity and mortality in patients with underlying cardiovascular diseases [1]. It is unclear whether patients with adult congenital heart disease (ACHD) should be considered as an increased risk population with poor outcomes when suffering from COVID-19 as they are typically younger than those with acquired cardiac disease and are less likely to have comorbidities [2]. On the other hand, the heterogeneity of this population makes the prediction of their response to COVID-19 very challenging. In a patient with ACHD, the severity of the disease is determined not only by defective anatomy or surgical repair but also by the current physiology, as physiological variables may have a prognostic value. According to the American Heart Association/American College of Cardiology Adult Congenital Heart Disease Guidelines, the more advanced physiological stage is characterized by the presence of moderate or greater valvular heart disease (stenosis or regurgitation), moderate/severe ventricular dysfunction, hypoxemia, hemodynamically significant shunt, arrhythmias, 
WHAT'S NEW?

It is unclear whether patients with adult congenital heart disease (ACHD) should be considered as an increased risk population with poor outcomes when suffering from COVID-19 as they are typically younger than those with acquired cardiac disease and are less likely to have comorbidities. We confirmed that anatomical complexity does not predict an adverse outcome. Decreased systemic ventricular systolic function and any significant valve stenosis were predictors of death or hospitalization. Our study showed that a physiology-based model, instead of an anatomy-based model, better predicts COVID-19 outcomes among ACHD patients. This information is important both for patients and medical care providers facing the next wave of COVID- 19 .

pulmonary arterial hypertension, Eisenmenger syndrome, or evidence of end-organ dysfunction [3]. Those with cyanotic lesions, genetic lesions, or an advanced physiological stage have been considered at the highest risk for moderate/severe COVID-19 [4, 5]. However, the results were based on small studies and need to be validated in a larger ACHD population. This study aimed to collect clinical outcome data and to identify risk factors of a complicated course of COVID-19 among ACHD patients.

\section{METHODS}

The study was conducted in a tertiary referral center for an ACHD as a retrospective registry of patients diagnosed with COVID-19. From all outpatients who had routine clinic appointments via telemedicine or direct physician contact at our institution between September 1, 2020 and March 31, 2021, we included all with a COVID-19 diagnosis (positive test for SARS-CoV-2 infection using a PCR test, antibody, and SARS-CoV-2 antigen-based ELISA or if someone had contact with an infected person in their household and developed typical symptoms).

The following variables of interest were demographic and historical medical data: body mass index (BMI), history of surgery for defects, a type of cardiac defect, the complexity of cardiac defect according to the European ACHD guidelines [6], New York Heart Association (NYHA) functional class before COVID-19, clinically relevant comorbidity, a clinical course, and an outcome of the COVID-19 disease. A severe COVID-19 was defined as death or the need for hospitalization requiring oxygen supply, non-invasive or invasive ventilation, or circulatory support. No need for hospitalization was defined as a mild course. Symptoms and infection duration were quantified and confirmed with the patient. A minimum temperature of $\geq 38.0^{\circ} \mathrm{C}$ was used to define fever. Echocardiographic data were collected from each patient's most recent echocardiogram within 12 months before infection. The following variables were assessed from standard transthoracic echocardiograms: significant (at least moderate) valvular stenosis or regurgitation (definition according to the ESC valvular heart disease guidelines), at least moderate systemic ventricular dysfunction (ejection fraction of systemic ventricular function at least $40 \%$ ), or any subpulmonic ventricular dysfunction. The diagnosis of pulmonary arterial hypertension had to be confirmed by cardiac catheterization.
The local research ethics board approved the study (IK-NPIA-0021-19/1901/2021). For this type of retrospective study, formal patient consent was not required.

\section{Statistical analysis}

Continuous variables were presented as the mean (standard deviation [SD]), and categorical variables were expressed as numbers and frequencies. A univariate logistic regression model was used to determine the odds ratios (ORs) and 95\% confidence intervals (Cls) for risk factors associated with hospitalization and/or death related to COVID-19. All variables with a significance threshold

Table 1. Characteristics of ACHD patients diagnosed with COVID-19

\begin{tabular}{|c|c|}
\hline Parameters & $N=104$ \\
\hline Age, years, mean (SD) & $38.5(12)$ \\
\hline Male, n (\%) & $48(46)$ \\
\hline $\mathrm{BMI}, \mathrm{kg} / \mathrm{m}^{2}$, mean (SD) & $25.5(4.2)$ \\
\hline Complex CHD, n (\%) & $28(26.9)$ \\
\hline Prior intervention, n (\%) & $60(57.6)$ \\
\hline Genetic syndrome, n (\%) & $7(6.7)$ \\
\hline Baseline oxygen saturation, \%, mean (SD) & $95.1(5.7)$ \\
\hline CHD-associated PAH, n (\%) & $10(9.6)$ \\
\hline Decreased systemic ventricular systolic function, n (\%) & $10(9.6)$ \\
\hline Decreased subpulmonary ventricular systolic function, n (\%) & $9(8.6)$ \\
\hline Significant valvular regurgitation (any), n (\%) & $26(25)$ \\
\hline Significant valvular stenosis (any), n (\%) & $10(9.6)$ \\
\hline Acquired comorbidities, $\mathrm{n}(\%)$ & $39(37.5)$ \\
\hline \multicolumn{2}{|l|}{ Medications } \\
\hline$\beta$-blockers, n (\%) & $44(42.3)$ \\
\hline ACE-I/ARB, n (\%) & $31(29.8)$ \\
\hline Diuretics, n (\%) & $21(20.2)$ \\
\hline Oral anticoagulation, $\mathrm{n}(\%)$ & $18(17.3)$ \\
\hline Antiplatelet therapy, n (\%) & $2(1.9)$ \\
\hline \multicolumn{2}{|l|}{ COVID-19 symptoms } \\
\hline Fever, n (\%) & $53(51)$ \\
\hline Cough, n (\%) & $49(47)$ \\
\hline Shortness of breath, n (\%) & $18(17)$ \\
\hline Fatigue, n (\%) & $71(68)$ \\
\hline Anosmia, n (\%) & $48(46)$ \\
\hline Ageusia, n (\%) & $46(44)$ \\
\hline Gastrointestinal symptoms, n (\%) & $14(13.5)$ \\
\hline Hospitalization, n (\%) & $5(4.5)$ \\
\hline Death, n (\%) & $2(1.9)$ \\
\hline None, n (\%) & $11(10.6)$ \\
\hline
\end{tabular}

Abbreviations: $\mathrm{ACEl}$, angiotensin-converting-enzyme inhibitors; $\mathrm{ARB}$, angiotensin receptor blockers; $\mathrm{BMI}$, body mass index; $\mathrm{CHD}$, congenital heart disease; $\mathrm{PAH}$, pulmonary arterial hypertension; SD, standard deviation 
Table 2. Characteristics of patients with severe COVID-19 infections

\begin{tabular}{|c|c|c|c|c|}
\hline Age & Sex & Main diagnosis & Clinical background & SARS-CoV-2 infection course \\
\hline 19 & Male & $\begin{array}{l}\text { Repaired tetralogy of Fallot, Down } \\
\text { syndrome }\end{array}$ & $\begin{array}{l}\text { NYHA class II, decreased RV function, } \\
\text { significant pulmonary stenosis, oxygen } \\
\text { saturation at rest } 94 \% \text {, BMl } 21 \mathrm{~kg} / \mathrm{m}^{2}\end{array}$ & $\begin{array}{l}\text { Hospitalization due to SARS-CoV-2 bilateral pneumo- } \\
\text { nia requiring non-invasive ventilation, fully recovered } \\
\text { after } 21 \text { days after hospital admission }\end{array}$ \\
\hline 51 & Female & Repaired tetralogy of Fallot & $\begin{array}{l}\text { NYHA class II, systemic hypertension, } \\
\text { BMI } 28.1 \mathrm{~kg} / \mathrm{m}^{2}\end{array}$ & $\begin{array}{l}\text { Death due to SARS-CoV-2 infection } 14 \text { days after } \\
\text { admission (ARDS related to COVID-19 requiring intuba- } \\
\text { tion), renal failure }\end{array}$ \\
\hline 36 & Female & $\begin{array}{l}\text { common arterial trunk type IV } \\
\text { (unrepaired) }\end{array}$ & $\begin{array}{l}\text { NYHA class II, permanent atrial flutter/ } \\
\text { atrial fibrillation, severely reduced bi- } \\
\text { ventricular function, oxygen saturation } \\
\text { at rest } 76 \%, \mathrm{BMI} 32.4 \mathrm{~kg} / \mathrm{m}^{2}\end{array}$ & $\begin{array}{l}\text { Hospitalization due to heart failure exacerbation, } \\
\text { SARS-CoV-2 infection during hospital stay worsening } \\
\text { the clinical course of the disease, died suddenly on day } \\
10 \text { after hospital admission }\end{array}$ \\
\hline 31 & Female & $\begin{array}{l}\text { unrepaired cyanotic CHD: single } \\
\text { ventricle, transposition of the } \\
\text { great arteries, significant pulmonary } \\
\text { stenosis }\end{array}$ & $\begin{array}{l}\text { NYHA class II, moderate mitral regurgi- } \\
\text { tation, oxygen saturation at rest } 94 \% \text {, } \\
\text { BMI } 17.5 \mathrm{~kg} / \mathrm{m}^{2}\end{array}$ & $\begin{array}{l}\text { Hospitalization due to bilateral pneumonia requiring } \\
\text { oxygen-therapy with a face mask fully recovered } \\
14 \text { days after hospital admission }\end{array}$ \\
\hline 51 & Female & $\begin{array}{l}\text { congenitally corrected transposition } \\
\text { of the great arteries, history of ASD } \\
\text { and VSD closure, and TV replacement }\end{array}$ & $\begin{array}{l}\text { NYHA class II/III, severe systemic RV dys- } \\
\text { function, permanent atrial fibrillation } \\
\text { BMI } 22.5 \mathrm{~kg} / \mathrm{m}^{2}\end{array}$ & $\begin{array}{l}\text { Hospitalization due to severe gastrointestinal symp- } \\
\text { toms of COVID-19 infection (gastritis) with subsequent } \\
\text { HF exacerbation (patient required inotropic agents), } \\
\text { fully recovered after } 28 \text { days }\end{array}$ \\
\hline
\end{tabular}

Abbreviations: ASD, atrial septal defect; NYHA, New York Heart Association class; TV, tricuspid valve; VSD, ventricular septal defect; other — see Table 1

of $P<0.01$ in the univariate model were included in the multivariable logistic regression analysis to identify independent predictors of a complicated SARS-CoV-2 infection course in ACHD patients. A two-sided $P$-value of $<0.05$ was considered statistically significant. All data were analyzed with an R software package version 4.0.0 (R Foundation, Vienna, Austria).

\section{RESULTS}

During 6 months of observation, 1197 patients were seen by cardiologists ( $28 \%$ were consulted via telemedicine) at our outpatient clinic for ACHD. The mean age of the entire cohort was $38.5 \pm 14$ years. In 243 (20.3\%) patients, a complex congenital cardiac defect was diagnosed. We identified 104 (8.7\%) patients who met our definition for a SARS-CoV-2 infection. Overall, 89 (86\%) patients had a diagnosis confirmed with testing, while in 15 (14\%) patients, the diagnosis was based on clinical grounds. Table 1 summarizes the baseline characteristics of ACHD patients diagnosed with COVID-19. Most patients reported a mild course of COVID-19 disease (99 [95.5\%]). Five patients (4.5\%) experienced severe symptoms and needed hospitalization. Two patients ( $1.9 \%$ of all with a confirmed diagnosis, $40 \%$ with severe infection) died.

Table 2 summarizes details on patient characteristics and clinical history of individuals with severe COVID-19.

In the univariable analysis, decreased systemic and subpulmonary ventricular systolic function, and any significant valvular stenosis were predictors of hospitalization and/or death. In the multivariable analysis, decreased systemic ventricular systolic function and any significant valve stenosis were predictors of a complicated disease course (Table 3).

\section{DISCUSSION}

This is the first sizable single-center report on the outcome of COVID-19 among ACHD patients in Europe. The main finding of our study is that decreased systemic ventricular
Table 3. Uni- and multivariable analysis for COVID-19 — related hospitalization and/or death

\begin{tabular}{lccc}
\multicolumn{1}{c|}{ Variable } & OR (95\% CI) & P-value \\
Univariable analysis & $1.00(0.93-1.08)$ & 0.98 \\
Age, years & $0.26(0.03-2.56)$ & 0.26 \\
Male sex & $1.11(0.18-6.91)$ & 0.96 \\
History of intervention & $4.44(0.70-28.12)$ & 0.11 \\
Complex CHD (vs. moderate/mild) & $3.88(0.37-40.29)$ & 0.26 \\
Genetic disorder & $0.95(0.37-1.08)$ & 0.41 \\
Baseline oxygen saturation & $0.93(0.74-1.16)$ & 0.52 \\
BMI, kg/m² & $2.5(0.25-24.83)$ & 0.43 \\
CHD-associated PAH & $2.63(0.42-16.45)$ & 0.30 \\
Acquired comorbidities & $7.58(1.10-52.23)$ & 0.04 \\
Decreased systemic ventricular & & \\
systolic function & $8.76(1.25-61.42)$ & 0.03 \\
Decreased subpulmonary ventricular & & \\
systolic function & $2.08(0.33-13.21)$ & 0.44 \\
Significant valvular regurgitation (any) & $7.58(1.10-52.23)$ & 0.04 \\
Significant valvular stenosis (any) & & \\
Multivariable analysis & $20.75(1.69-254.74)$ & 0.02 \\
$\begin{array}{l}\text { Decreased systemic ventricular } \\
\text { systolic function }\end{array}$ & $20.75(1.69-254.74)$ & 0.02 \\
Significant valvular stenosis (any) & &
\end{tabular}

Abbreviations: OR, odds ratio; other — see Table 1

function and significant valvular stenosis identify patients with a severe course of COVID-19. Our results are in agreement with the real-world data, which has already been published and confirmed the thesis that anatomical complexity itself does not predict an adverse outcome. In the first publication by Lewis et al., the authors concluded that an ACHD Physiological Stage C or D was associated with a moderate/severe COVID-19. Moderate/severe ventricular dysfunction and at least moderate valvular stenosis were among the criteria that placed patients at Physiological Stage C or D. Similarly, Broberg et al. [7] found that reduced subaortic ventricular function was predictive of a severe course. In the work by Ruperti-Repilado et al. [8], more than $90 \%$ of ACHD experts pointed out that pulmonary arterial hypertension (PAH), cyanotic heart disease, and 
Fontan palliation are the most important factors of an unfavorable outcome. In our analysis, neither baseline oxygen saturation, $\mathrm{PAH}$, nor ACHD complexity were important as outcome predictors. These results provide important knowledge regarding our current perception of risks and shift us away from an anatomy- to a physiology-based model.

In the article by Schwerzmann et al. [4], the authors demonstrated that general risk factors (age, obesity, and multiple comorbidities) may predict a complicated course of COVID-19. Obesity is a well-known risk factor for a severe course of COVID-19, along with hospitalization, transferto the intensive care unit, being put on a ventilator, and, finally, dying [10]. This was not the case in our study as in our cohort the mean BMI was $25.5 \mathrm{~kg} / \mathrm{m}^{2}$ - much lower than reported by others $[3,7]$. Acquired comorbidities (systemic hypertension, diabetes, atrial fibrillation, or ischemic heart disease) are infrequent in the ACHD population. We found them in 39 (37.5\%) cases and did not demonstrate they influenced the COVID-19 outcome. Older age was a risk factor for COVID-related death in ACHD and the general population. In our population, it has not been shown to be an important prognostic factor. Although the mean age and the frequency of acquired cardiac risk factors were comparable with previously published reports, this phenomenon remains to be explained.

This is the first study in which an attempt was made to determine the rate of infection among the ACHD population. In a small series of patients with Fontan circulation from Italy, the authors estimated that the 1-year COVID-19 incidence was $11 \%$ [11]. During the autumn and winter of 2020/2021, our outpatient clinic treated 1197 ACHD patients. Yet only 104 (8.7\%) of them were COVID-19 positive. Of these, only 5 patients had a severe course and 2 died, resulting in an overall case/fatality ratio (in those tested) of 1.9\%. Broberg et al. [7] reported a similar case/fatality ratio at the level of $2.3 \%$. Our results concern the period before the common vaccination program and during the first year of the COVID-19 pandemic.

The ACHD patients are known to greatly benefit from prompt access to continuous expert care. Authors from Italy reported cancellation of all elective hospital procedures during the first year of the COVID-19 pandemic but stable the overall number of urgent hospital admission during that time [12]. Our center did not restrict access to medical care. In response to patients' requests, we implemented new alternative ways of communication. Twenty-eight percent of consultations were carried out using telemedicine.

The spectrum of COVID-19 symptoms in our population was like those described in other ACHD cohorts [13], with fatigue and fever being the most frequent (68\% and 51\%, respectively). Notably, $10.6 \%$ of patients were completely asymptomatic; diagnoses were made incidentally through COVID-19 PCR testing, after a known exposure, or through the SARS-CoV-2 antibody test. As the ACHD population is relatively young, the real proportion of patients who had COVID-19 may be higher.

\section{Study limitations}

The limitation of our study is its retrospective design. We did not test every patient treated at our outpatient clinic for SARS-CoV-2. As we know, some patients have asymptomatic infections; this implies that other asymptomatic carriers were likely to be among this population. The preceding limitations suggested that the true case/fatality ratio might be lower, and on the other hand, the rate of SARS-CoV-2 infections might be higher. Our study focused on short-term death and serious complications and did not address potential medium and long-term complications. Further studies on the longer-term consequences of COVID-19 in ACHD are needed. We are also aware that the logistic regression model performed for our dataset with few events involves some uncertainty, and the results should be interpreted with caution.

\section{CONCLUSIONS}

In conclusion, our study confirmed previous results showing that a physiology-based model, instead of an anatomy-based model, better predicts COVID-19 outcomes among ACHD patients. This information is important both for patients and medical care providers facing the next stage of the pandemic.

\section{Article information}

Acknowledgments: The authors thank Robin Krauze for her invaluable remarks and language help.

Conflict of interest: None declared.

Open access: This article is available in open access under Creative Common Attribution-Non-Commercial-No Derivatives 4.0 International (CC BY-NC-ND 4.0) license, allowing to download articles and share them with others as long as they credit the authors and the publisher, but without permission to change them in any way or use them commercially. For commercial use, please contact the journal office at kardiologiapolska@ptkardio.pl.

\section{REFERENCES}

1. Fried JA, Ramasubbu K, Bhatt R, et al. The variety of cardiovascular presentations of COVID-19. Circulation. 2020; 141(23): 1930-1936, doi: 10.1161/CIRCULATIONAHA.120.047164, indexed in Pubmed: 32243205.

2. Diller GP, Gatzoulis MA, Broberg CS, et al. Coronavirus disease 2019 in adults with congenital heart disease: a position paper from the ESC working group of adult congenital heart disease, and the International Society for Adult Congenital Heart Disease. Eur Heart J. 2021; 42(19): 1858-1865, doi: 10.1093/eurheartj/ehaa960, indexed in Pubmed: 33313664.

3. Stout KK, Daniels CJ, Aboulhosn JA, et al. 2018 AHA/ACC Guideline for the Management of Adults With Congenital Heart Disease: A Report of the American College of Cardiology/American Heart Association TaskForce on Clinical Practice Guidelines. J Am Coll Cardiol. 2019; 73(12): e81-e8e192, doi: 10.1016/j.jacc.2018.08.1029, indexed in Pubmed: 30121239.

4. Schwerzmann M, Ruperti-Repilado FJ, Baumgartner $\mathrm{H}$, et al. Clinical outcome of COVID-19 in patients with adult congenital heart disease. Heart. 2021 [Epub ahead of print], doi: 10.1136/heartjnl-2020-318467, indexed in Pubmed: 33685931.

5. Lewis MJ, Anderson BR, Fremed M, et al. Impact of Coronavirus Disease 2019 (COVID-19) on Patients With Congenital Heart Disease Across the Lifespan: The Experience of an Academic Congenital Heart Disease 
Center in New York City. J Am Heart Assoc. 2020; 9(23): e017580, doi: 10.1161/JAHA.120.017580, indexed in Pubmed: 33196343.

6. Baumgartner H, De Backer J, Baumgartner H, et al. 2020 ESC Guidelines for the management of adult congenital heart disease. Eur Heart J.2021;42(6): 563-645, doi: 10.1093/eurheartj/ehaa554, indexed in Pubmed: 32860028.

7. Broberg CS, Kovacs AH, Sadeghi S, et al. Coronavirus disease 2019 in adults with congenital heart disease: a position paper from the ESC working group of adult congenital heart disease, and the International Society for Adult Congenital Heart Disease. Eur Heart J. 2021;42(19): 1858-1865, doi: 10.1093/eurheartj/ehaa960, indexed in Pubmed: 33313664.

8. Ruperti-Repilado FJ, ToblerD, Greutmann M, etal. Risk stratification of adults with congenital heart disease during the COVID-19 pandemic: insights from a multinational survey among European experts. Open Heart. 2021; 8(1), doi: 10.1136/openhrt-2020-001455, indexed in Pubmed: 33883228.

9. Abbasi J. Large meta-analysis digs into obesity's COVID-19 risks. JAMA. 2020; 324(17): 1709-1711, doi: 10.1001/jama.2020.18637, indexed in Pubmed: 33057567.
10. Pawlak A, Dreżewski K, Szymański P, et al. Cardiovascular disease, therapy, and mortality of oligosymptomatic and symptomatic patients infected with SARS-CoV-2: experiences of a designated hospital in Poland. Kardiol Pol. 2020; 78(11): 1162-1165, doi: 10.33963/KP.15596, indexed in Pubmed: 32897038

11. Fusco F, Scognamiglio G, Merola A, et al. Coronavirus disease 2019 in patients with Fontan circulation. IJC Congenital Heart Disease. 2021; 3: 100126, doi: 10.1016/j.jijcchd.2021.100126.

12. Scognamiglio G, Fusco F, Merola A, et al. Caring for adults with CHD in the era of coronavirus disease 2019 pandemic: early experience in an Italian tertiary centre. Cardiol Young. 2020; 30(10): 1405-1408, doi: 10.1017/S1047951120002085, indexed in Pubmed: 32624052.

13. Tan $\mathrm{W}$, Aboulhosn J. The cardiovascular burden of coronavirus disease 2019 (COVID-19) with a focus on congenital heart disease. Int J Cardiol. 2020; 309: 70-77, doi:10.1016/j.jijcard.2020.03.063, indexed in Pubmed: 32248966 . 